\begin{tabular}{|c|c|c|}
\hline $\mathrm{Ar}$ & $\begin{array}{c}\text { European Association for the } \\
\text { Development of Renewable Energies, Environment } \\
\text { and Power Quality (EA4EPQ) }\end{array}$ & $\begin{array}{l}\text { International Conference on Renewable Energies and Power Quality } \\
\text { (ICREPQ'12) } \\
\text { Santiago de Compostela (Spain), 28th to 30th March, } 2012\end{array}$ \\
\hline
\end{tabular}

\title{
Control Design for a Power Electronic Based Fault Current Limiter (FCL)
}

\author{
C. Hahn ${ }^{1}$, M. Weiland ${ }^{1}$, G. Herold ${ }^{1}$ \\ ${ }^{1}$ Institute of Electrical Power Systems \\ University of Erlangen-Nuremberg \\ Cauerstraße 4 - Building 1, D-91052 Erlangen (Germany) \\ Phone/Fax number: +49 9131 8523452, e-mail: christoph.hahn@ees.uni-erlangen.de, weiland@eev.eei.uni-erlangen.de, \\ herold@eev.eei.uni-erlangen.de
}

\begin{abstract}
This paper shows a solution for controlling shortcircuit currents of a power electronic based Fault Current Limiter (FCL). A model for control design of three-phase short-circuit currents will be presented. A way of limiting the maximum aperiodic short-circuit current is derived with special regards to the stability of the entire system. Control designs of single- and two-phase shortcircuit currents are shown in the paper as well as a method of fault type detection.
\end{abstract}

\section{Key words}

FCL, control design, short-circuit current, maximum aperiodic short-circuit current, fault detection.

\section{Introduction}

The use of fault current limiters in electrical grids with a high short-circuit power is of high importance. The short circuit current is an essential indicator for the mechanical and thermal stress of a system. Methods of limiting short circuit currents by the use of thyristor converters are already known for quite a long time [1], [2]. Fault current limiters can be used to reduce arc flash energy in electrical grids [3] and they offer an easy opportunity to reduce the short-circuit currents in a fast way. Hence, other and slower short circuit current protective devices are capable to locate the fault and switch it off. Fault current limiters offer a very elegant way to switch off the short-circuit current or reduce it to a specific value. The reduction to this specific value can be either done by setting the firing angle to a constant value or by controlling the short-circuit current. An approach of setting the firing angle to a certain value has already been presented in [4]. This method introduces the disadvantage of not being able to control the short-circuit current. The now proposed method of controlling the short-circuit current has the big advantage of being able to forecast the mechanical and thermal stress for cables, transformers, generators and other system elements. This forecast is not as easy if the firing angle is set to a constant value due to the short-circuit current will be unknown. As electrical systems are normally operated without faults, there are also control strategies for FCLs in no-fault operation known [5]. First, this paper will show the structure and functional principle of a fault current limiter. Afterwards a model for control design will be determined and it will be shown that the short-circuit current can be controlled to a steady-state value. It will be shown how to choose the parameters of the controller in order to determine an exact and stable system behaviour.

\section{Structure and functional principle of the FCL}

The FCL, shown in Figure 1, is directly installed in the transformers neutral terminal. The FCL consists of a six-pulse thyristor rectifier $\left(T_{1}\right.$ to $\left.T_{6}\right)$, a diode valve branch $\left(V_{7}\right.$ and $\left.V_{8}\right)$, a freewheeling arm and an ohmic-inductive arm represented by $R_{d}$ and $L_{d}[6]$.

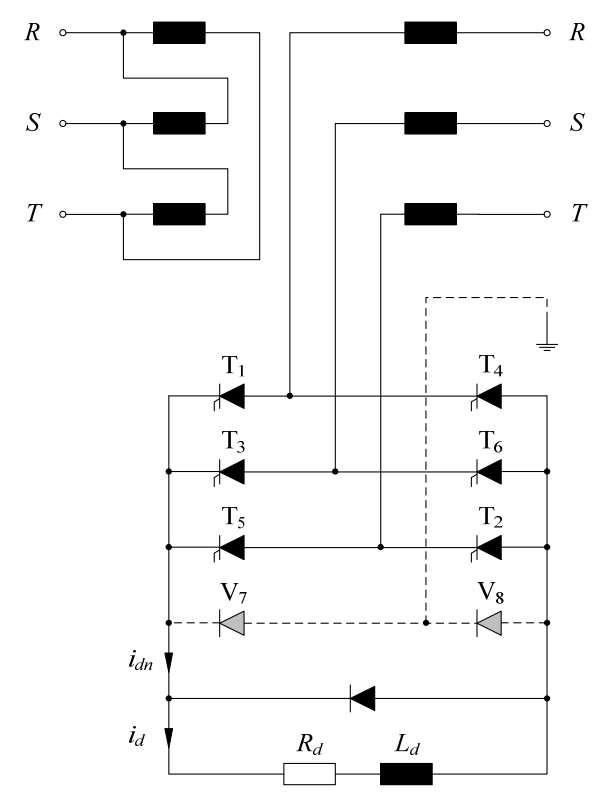

Figure 1: Fault Current Limiter (FCL) on a Diii-transformer

In case of no fault the thyristors are fired in their natural firing point and they behave like diodes in principle. Only in case of a fault the firing angle will be changed and the short 
circuit current will be limited actively. The inductance $L_{d}$ will limit the rise of the short-circuit current. If the voltage across the choke falls under the threshold voltage of the diode, the freewheeling arm becomes active. In steady-state mode the currents in the FCL are not distorted.

For controlling the short-circuit current only the behaviour in fault case will be discussed here. In fault case the currents will rise very fast, what directly induces the d.c. current to rise very fast too. The whole d.c. current has to flow through the coil and depending on its size it will convert to the steadystate value with or without an overshoot [6]. The task of the controller is to limit the possible overshoot on the one hand, as well as controlling the short-circuit current to a certain steadystate value on the other hand.

In fault case, the FCL operates in basically six operation modes. These operation modes are commutation with a conducting freewheeling diode, commutation with a blocking freewheeling diode, two conducting thyristor valves at a blocking freewheeling diode, two conductive thyristors with a conducting freewheeling diode, intermittent d.c. flow with a blocking freewheeling diode and intermittent d.c. flow with a conducting freewheeling diode. For each state a mathematical description can be obtained by transforming the circuit into the state of the space phasor and solving the appropriate differential equations [7]. For these mathematical transformations, in freewheeling case, the diode can be replaced by a voltage source in series with a resistor; whereby the voltage source is equivalent to the threshold voltage of the diode and the resistor describes the internal resistance of the diode. Once the freewheeling diode is blocking, it can be neglected.

\section{Controlling a Three-Phase Short-Circuit Current of a FCL}

Controlling the short-circuit current can be essential for many reasons. It is not always a general advantage to switch off the short-circuit current immediately. Other protective devices request a certain fault current to switch off regarding to their purpose. Locating the fault place could be one of the purposes.

\section{A. Identification of the system behaviour}

Before one can determine a controller for the FCL, it is mandatory to analyse the system behaviour of the FCL. The best way is analysing the system behaviour for the so called "Worst Case". All the other operation modes are less critical and are also covered by this. Hence it occurred that the FCL shows the most dynamic reactions if it is working in a diode similar operation mode, which means all the thyristors are fired close to their natural firing points. The impedance ratio is $Z_{d} / Z_{k}=0$, where $Z_{k}$ is the short-circuit impedance of the system. Figure 2 shows the short-circuit current at a threephase fault at a preset firing angle of $30^{\circ}$.

The maximum aperiodic short-circuit current is already damped through the short "two conductive thyristor valves mode" at the beginning ( $2 \mathrm{~ms}<t<4 \mathrm{~ms}$ ). Whereby the $R / X$ - ratio of the short-circuit impedance is $R_{k} / X_{k}=0.1$. Looking at Figure 2 reveals that the envelope of the shortcircuit currents is looking like a second order delay with the transfer function [8]:

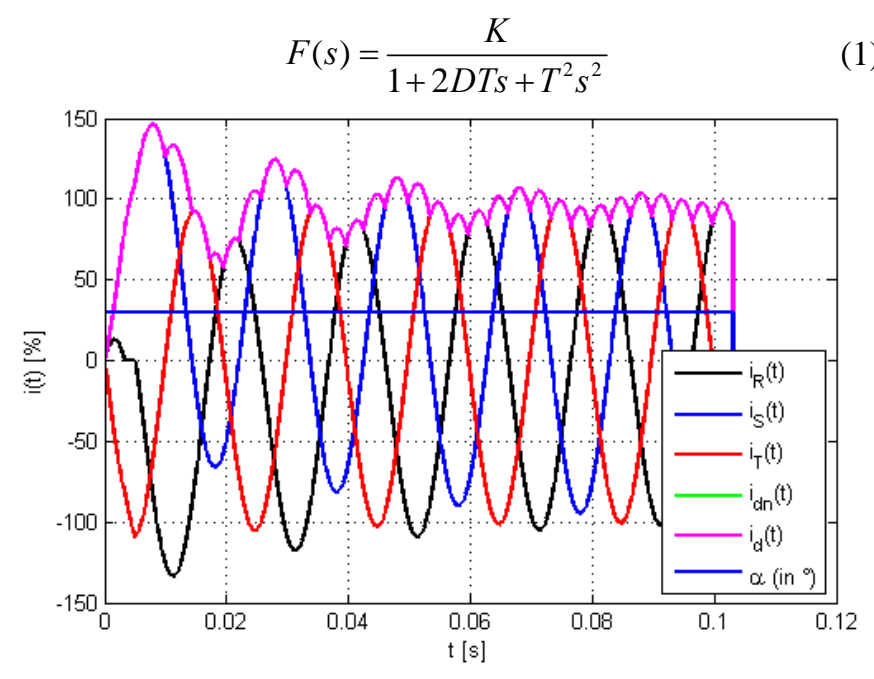

Figure 2: Short-circuit currents at a three-phase fault at a preset firing angle of $30^{\circ}$ and $Z_{d} / Z_{k}=0$

Thereby $K$ is the gain, $D$ is the damping and $T$ is the time constant of the system. With the help of [8] they can be obtained directly out of Figure 2:

$$
\begin{aligned}
& K \approx 100, \\
& D \approx 0.25, \\
& T \approx 0.0029 .
\end{aligned}
$$

The transfer function of the system can now be written as follows:

$$
F(s)=\frac{100}{1+0,0014 s+8,35 * 10^{-6} s^{2}}
$$

Thereby all values are normalized to their S.I. units.

\section{B. Design of a basic controller regarding the system behaviour}

The in equation (3) described delay second order has complex-conjugated poles. Hence it is not achievable to design a controller by the method of eliminating the poles. Figure 3 shows the control structure of the FCL, where $i_{d n}(t)$ is the designated short-circuit current and $\alpha$ is the firing angle of the system.

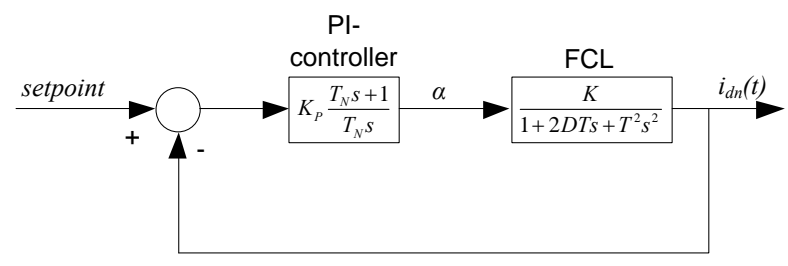

Figure 3: Control structure of the FCL

The aim is to find a controller which is fast and also able to reach an exact steady-state. The system behaviour offers the usage of a simple PI-controller. This type of controller already provides an exact steady-state and the speed can be chosen by the parameters of the controller. The transfer function of the PI-controller is shown in equation (4). 


$$
F_{R}(s)=K_{p} \frac{1+T_{N} s}{T_{N} s}
$$

Thereby $K_{P}$ is the controller gain and $T_{N}$ is the time constant of the controller.

A controller can be obtained by the method of design with the help of the frequency response characteristic. At first one has to choose the time constant of the controller in order to get the range of the crossover frequency as far as possible to the right side in the bode chart regarding the speed of the control loop. The next step is to choose the gain of the controller in a way to save a certain phase margin in order to secure the stability of the system. Figure 4 shows the bode chart of the open-loop system with a controller gain of $K_{p}=1.4$ and a controller time constant of $T_{N}=0.001$.

Approaching this theory it is also possible to choose the controller time constant faster than it was chosen here in order to speed up the control loop. But the FCL is a non-linear system. The thyristors are fired every $60^{\circ}$ plus the respective changes in the firing angle. Within this $60^{\circ}$ every change of the firing angle has no effect on the FCL. Thus, instabilities might occur only through the nonlinearity of the system if the controller time constant is too fast.
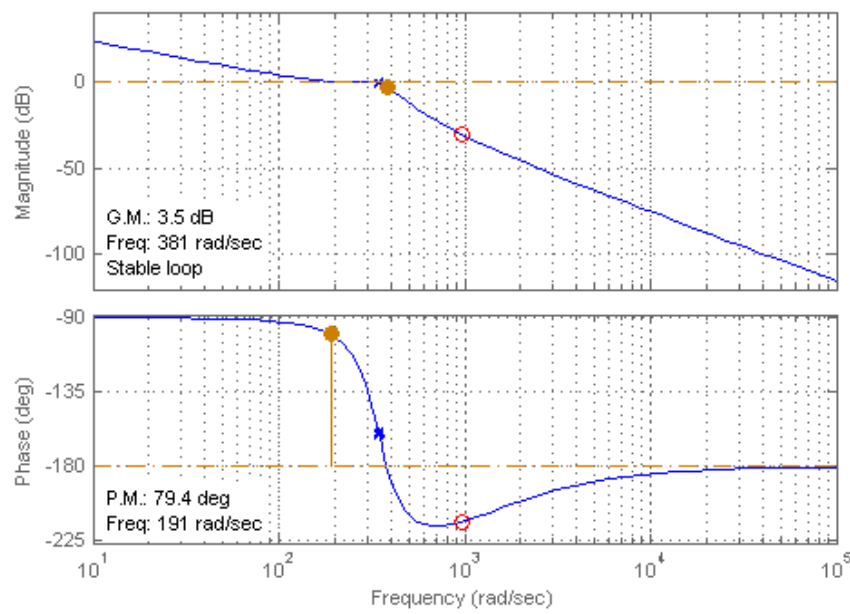

Figure 4: Open-loop bode chart for the controlled system

Figure 5 shows the short-circuit currents and the firing angle of the controlled system. Thereby the controller gain is $K_{p}=1.4$ and the controller time constant is $T_{N}=0.001$. The setpoint of the control loop is $50 \%$. In the first converter period the setpoint is held to a constant value of $30^{\circ}$ in order to ensure there is enough time to indicate the short-circuit. After that short time interval the controller intervenes and gets the short-circuit current to its aspired steady-state value.

To show the functionality of the controller, it is also mandatory to demonstrate that the system is also stable for large impedance ratios $Z_{d} / Z_{k}$. Figure 6 shows that the controller is stable for an impedance ratio of $Z_{d} / Z_{k}=10$. The maximum aperiodic short-circuit current is already damped due to the high value of the impedance $Z_{d}$. Furthermore it has to be mentioned that the firing angle can reach negative values; this is the so called forward displacement of the firing angle.

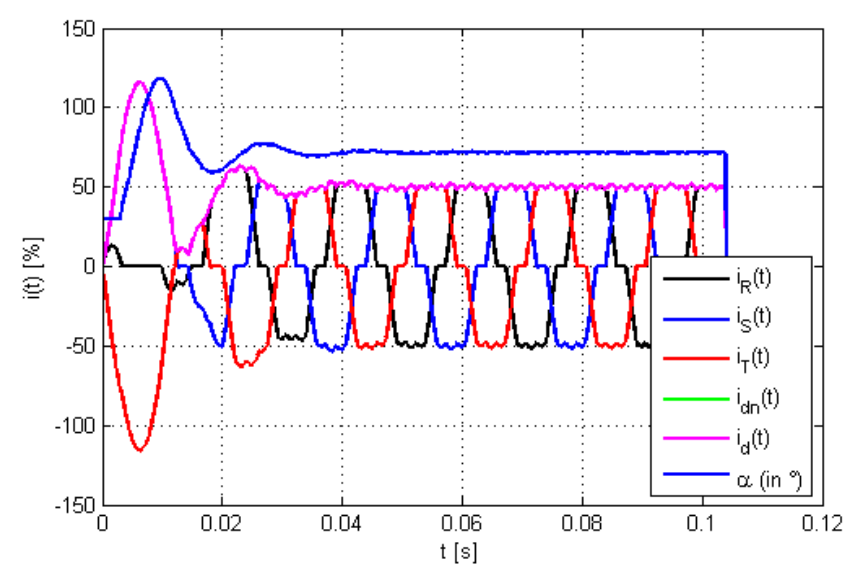

Figure 5: Controlled short-circuit currents at a three-phase fault for $Z_{d} / Z_{k}=0, K_{p}=1.4$ and $T_{N}=0.001$

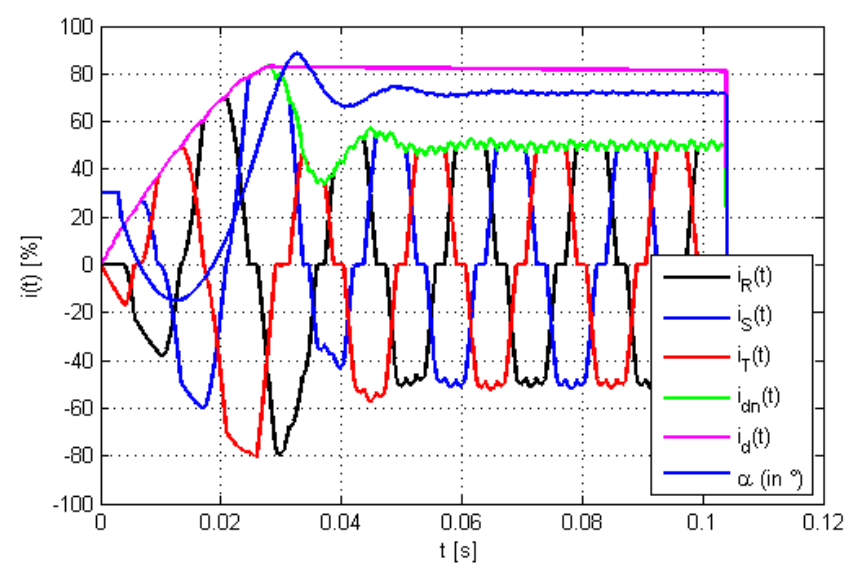

Figure 6: Controlled short-circuit currents at a three-phase fault for $Z_{d} / Z_{k}=10, \quad K_{p}=1.4$ and $T_{N}=0.001$

\section{Design of a controller regarding the maximum aperiodic short-circuit current}

As mentioned in the previous section the FCL is a nonlinear system due to the firing delay of $60^{\circ}$ on average. This firing delay is equal to a dead-time element. During this interval of $60^{\circ}$ the FCL is not capable to interact. The transfer function of such a dead-time element can be described as follows [8].

$$
F_{t}(s)=\mathrm{e}^{-T_{t} s}
$$

Where $T_{t}$ is the dead-time, which is basically the $60^{\circ}$ firing delay, which has to be transformed in a time base.

$$
T_{t}=\frac{60^{\circ}}{360^{\circ}} T=\frac{1}{6} \frac{1}{f}=\frac{1}{6} \frac{1}{50 \mathrm{~Hz}}=0,00 \overline{3} \mathrm{~s}
$$

Of course the dead-time element is also a non-linear element and hence the transfer function is non-linear. It can be linearized by decomposing the inverse transfer function in a Taylor series and truncating the Taylor series after the first order derivatives. After the linearization the dead-time element can be illustrated as a simple delay first order element. 


$$
F_{t}(s) \approx \frac{1}{1+T_{t} s}
$$

Deploying a PI-controller to the system suggests choosing the controller time constant equal to the dead-time. In this case the pole of the linearized death-time element can be eliminated by the controller. For stability reasons it is not advisable to choose any controller time constants which are faster than the death-time, even if it works, like it was shown in the previous section.

Figure 7 shows the short-circuit currents and the firing angle of the controlled system. In order to limit the maximum aperiodic short-circuit current one has to look at the second (green marked) peak in Figure 7. The first (and lower) peak (on the left hand side of the maximum peak) is given by the system. Once the short-circuit arises, the first peek will occur in any case due to the thyristors are already fired. The only thing that could be influenced is the second peak by firing the thyristors at the right time.

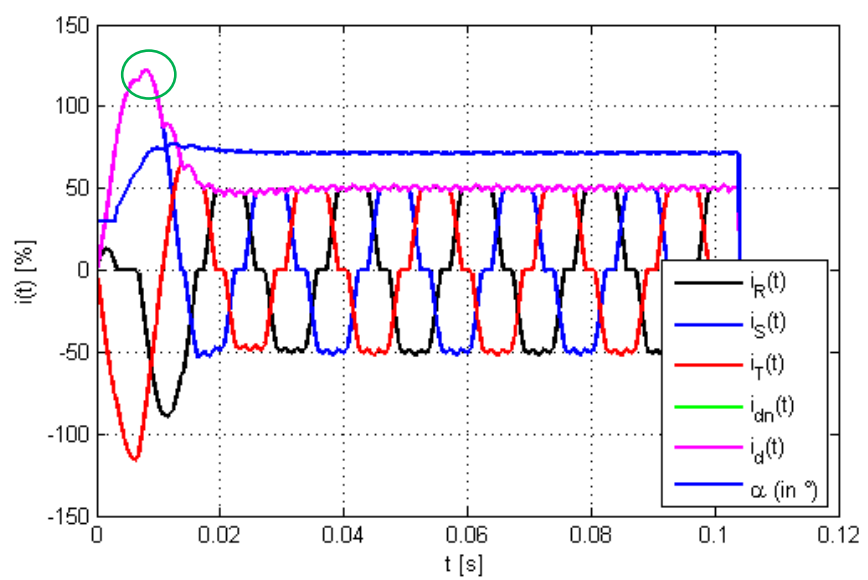

Figure 7: Controlled short-circuit currents at a three-phase fault for

$$
Z_{d} / Z_{k}=0, K_{p}=1.4 \text { and } T_{N}=0.00 \overline{3}
$$

The controller time constant was already chosen to the time constant of the death-time element. Hence one has to choose the controller gain in a way to set the maximum of the second peak below the maximum of the first peak. Then one can reach the maximum damping of the aperiodic short-circuit current.

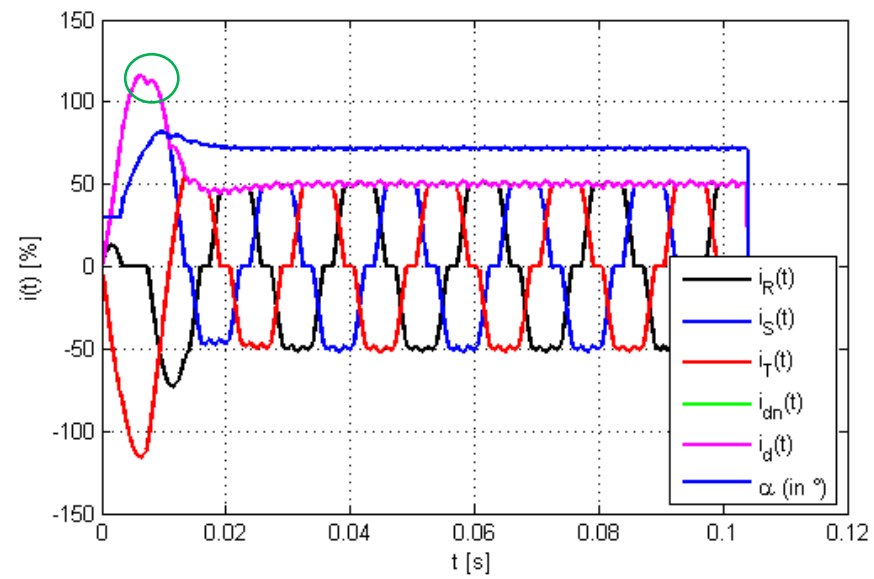

Figure 8: Controlled short-circuit currents at a three-phase fault for

$$
Z_{d} / Z_{k}=0, K_{p}=1.8 \text { and } T_{N}=0.00 \overline{3}
$$

Figure 8 shows the short-circuit currents and the firing angle of the controlled system. The controller gain was increased to $K_{p}=1.8$ and the green marked area shows that the second peak has fallen below the first peak of the shortcircuit current.

This approach gives the maximum effort that can be obtained regarding to damp the aperiodic short-circuit current and to guarantee the stability of the system.

\section{Controlling Single- and Two-Phase Short- Circuit Currents of a FCL}

This section will show single- and two-phase short circuit currents can basically be controlled with the same controller as it is used for a three-phase short-circuit. Thereby for a twophase short-circuit current changes in the firing impulse generator are required.

\section{A. Controlling single-phase short-circuit currents of a FCL}

As mentioned above there are no bigger changes required for controlling single-phase short-circuit currents. Because there is no longer a commutation operation mode existing, the firing pulse width has to be increased. Using a firing pulse width of $50^{\circ}$ ensures that the next thyristor can be fired, even if the current in the previous thyristor is not zero yet, after it became zero in the previous valve.

Figure 9 shows the single-phase short-circuit current and the firing angle of the controlled system for a single-phase fault in line $R$.

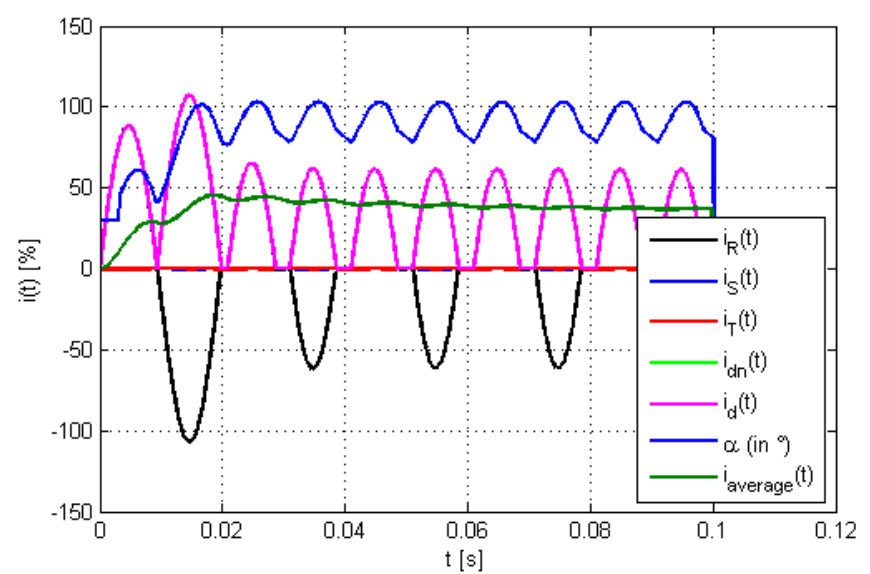

Figure 9: Controlled short-circuit currents at a single-phase fault for

$$
Z_{d} / Z_{k}=0, \quad K_{p}=1.8 \text { and } T_{N}=0.00 \overline{3}
$$

A setpoint of $30 \%$ of the nominal short-circuit current was chosen. Figure 9 shows that the average value of the shortcircuit current is controlled stable to a steady-state of $30 \%$.

\section{B. Controlling two-phase short-circuit currents of a FCL}

Two-phase short circuit currents require some bigger changes in the firing impulse generator. The single thyristors are fired each $60^{\circ}$ on average. If a two-phase short-circuit occurs, e.g. between the lines $S$ and $T$, there are pairs of thyristors which have to be fired at the same time. For a fault between $S$ and $T, \mathrm{~T}_{2}$ and $\mathrm{T}_{3}$ have to be fired at the same time as well as $T_{5}$ and $T_{6}$ have to be fired at the same time. There are basically two ways existing to handle this problem. The 
first way is to increase the firing pulse width up to more than $60^{\circ}$. If the pulse width is for example $100^{\circ}$, the coverage of neighbouring firing pulses is $40^{\circ}$ on average. Figure 10 shows the described coverage of neighbouring firing pulses depending on the pulse width.

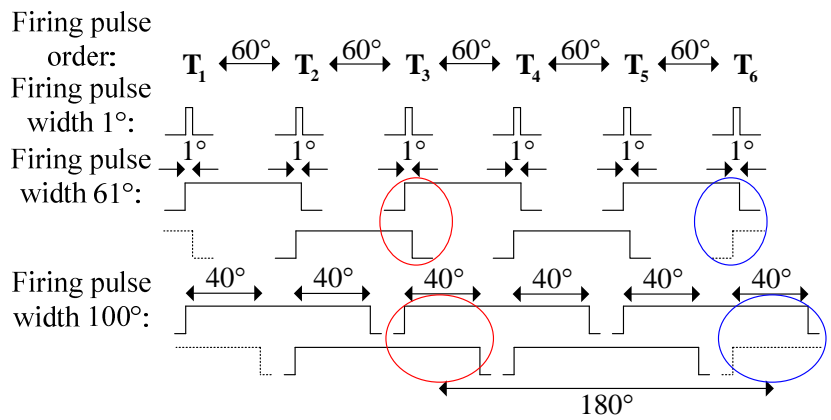

Figure 10: Coverage of the firing pulses depending on the pulse width

With this changes in the firing impulse generator the thyristors $T_{2}$ and $T_{3}$ and the thyristors $T_{5}$ and $T_{6}$, respectively, can be fired at the same time, which makes it possible to control two-phase short-circuit currents. Figure 11 shows the short-circuit currents and the firing angle of the controlled system for a two-phase fault between the lines $S$ and $T$.

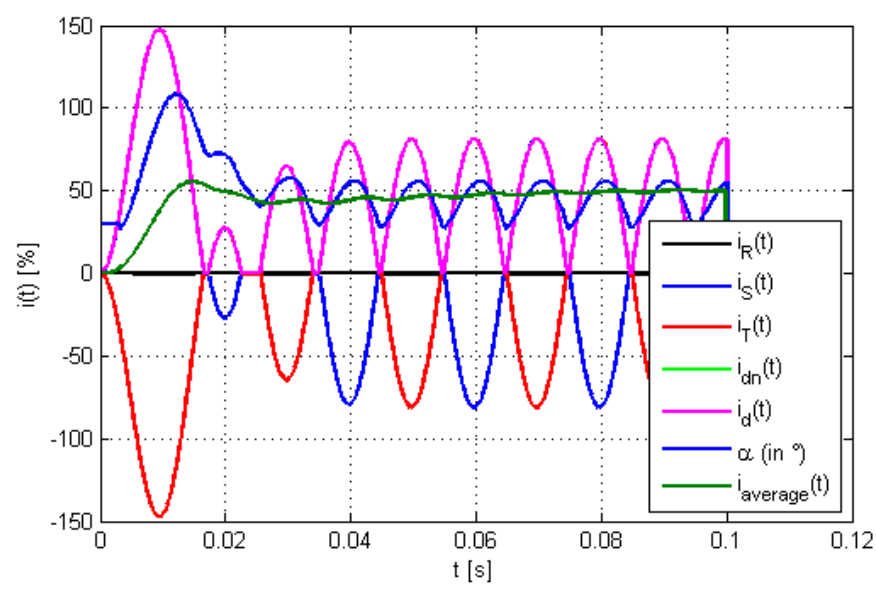

Figure 11: Controlled short-circuit currents at a two-phase fault for $Z_{d} / Z_{k}=0, K_{p}=1.8$ and $T_{N}=0.00 \overline{3}$ with pulse width $100^{\circ}$

Increasing the width of the firing pulses up to $100^{\circ}$ might cause some problems in controlling three-phase short-circuit currents; hence another opportunity in controlling two-phase short-circuit currents is to use two firing impulse generators instead of one. Depending on the type of fault the firing impulses have to be received either by the first firing impulse generator or by the $60^{\circ}$ shifted second firing impulse generator. Table 1 shows which valves are involved in controlling, depending on the type of fault. The valves in the second column are fired by the first firing impulse generator. The valves in the first column are fired by the second, $60^{\circ}$ shifted, firing impulse generator.
Table 1: Conducting valves depending on the fault type

\begin{tabular}{|l|l|c|}
\hline \multicolumn{2}{|l|}{ Conducting valves } & Type of fault \\
\hline $\mathrm{T}_{2}+60^{\circ}$ & $\mathrm{T}_{3}$ & Two-phase fault in \\
\hline $\mathrm{T}_{5}+60^{\circ}$ & $\mathrm{T}_{6}$ & Two-phase fault in $T$ \\
\hline $\mathrm{T}_{1}+60^{\circ}$ & $\mathrm{T}_{2}$ & $R$ and $T$ \\
\hline $\mathrm{T}_{4}+60^{\circ}$ & $\mathrm{T}_{5}$ & Two-phase fault in \\
\hline $\mathrm{T}_{6}+60^{\circ}$ & $\mathrm{T}_{1}$ & $R$ and $S$ \\
\hline $\mathrm{T}_{3}+60^{\circ}$ & $\mathrm{T}_{4}$ & \\
\hline
\end{tabular}

Using this method requires the opportunity of fault detection. Only if the right fault is detected, the firing impulses from the appropriate firing impulse generator are switched through and the fault can be handled in the right way.

Fault detection can be done by comparing the line currents of the FCL. The first step is to form the sum of each line current with another line current. If a two-phase short-circuit e.g. between the lines $S$ and $T$ occurs, the sum of the line currents $i_{S}(t)$ and $i_{T}(t)$ has to be zero. The same applies to faults in the lines $R, S$ and $R, T$ respectively.

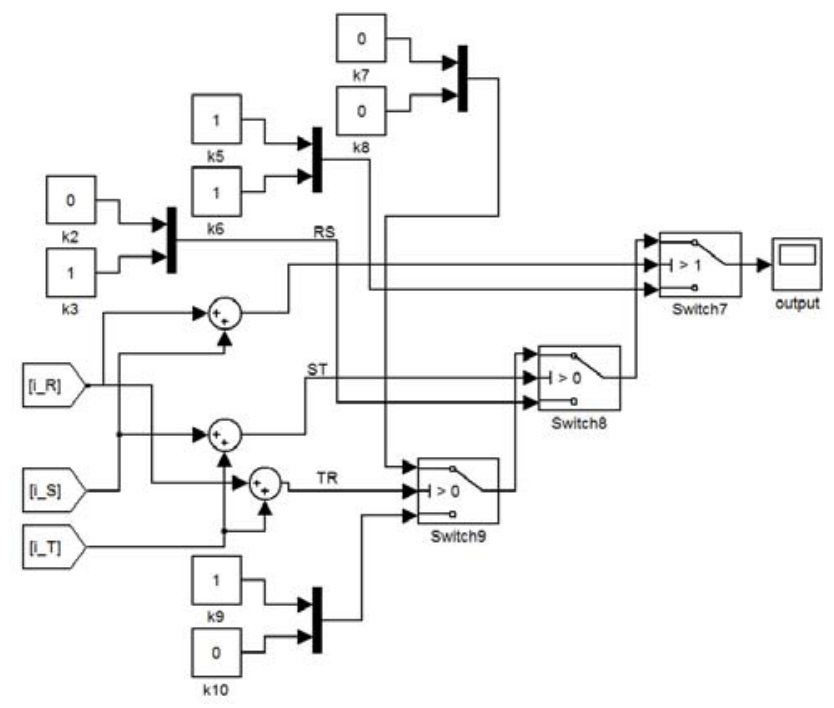

Figure 12: Fault detection logic in SIMULINK

Figure 12 shows the described fault detection logic. Each type of fault has its own error code. If one of the three sums is zero, the appropriate error code is switched to the output. If none of the sums is zero, the error code for the three-phase short-circuit is switched to the output. It is not necessary to detect the single-phase fault type due to every switching mode in Table 1 will be capable to handle one-phase short-circuit currents.

Table 2: Allocation of the error codes to the type of fault

\begin{tabular}{|l|c|}
\hline Type of fault & Error code \\
\hline Two-phase fault in $R$ and $T$ & 10 \\
\hline Two-phase fault in $S$ and $T$ & 01 \\
\hline Two-phase fault in $R$ and $S$ & 11 \\
\hline Three-phase fault & 00 \\
\hline
\end{tabular}


Table 2 shows the allocation of the error codes to the type of fault. These error codes provide a so called combinatorial logic block. This combinatorial logic block decides which firing impulse is switched on each thyristor depending on the error code.

Table 3 - Logic table for the evaluation of the contributing firing impulse generators

\begin{tabular}{|c|c|c|c|c|}
\hline Ehyristor & 00 & 01 & 10 & 11 \\
\hline $\mathrm{T}_{1}$ & 1 & $\mathrm{X}$ & 0 & 1 \\
\hline $\mathrm{T}_{2}$ & 1 & 0 & 1 & $\mathrm{X}$ \\
\hline $\mathrm{T}_{3}$ & 1 & 1 & $\mathrm{X}$ & 0 \\
\hline $\mathrm{T}_{4}$ & 1 & $\mathrm{X}$ & 0 & 1 \\
\hline $\mathrm{T}_{5}$ & 1 & 0 & 1 & $\mathrm{X}$ \\
\hline $\mathrm{T}_{6}$ & 1 & 1 & $\mathrm{X}$ & 0 \\
\hline
\end{tabular}

Table 3 shows the logic table for the evaluation of the contributing firing pulse generators. If a three-phase fault occurs (error code: 00) all thyristors are fired by firing impulse generator 1 (code: 1). If a two-phase fault in $S$ and $T$ occurs (error code: 01 ) thyristor $\mathrm{T}_{3}$ and $\mathrm{T}_{6}$ are fired by firing impulse generator 1 (code: 1 ) and the thyristors $T_{2}$ and $T_{5}$ are fired by firing impulse generator 2 (code: 0 ). The thyristors $T_{1}$ and $\mathrm{T}_{4}$ are not conductive, hence they can be fired either by generator 1 or 2 (code: $\mathrm{X}$ ). The same applies to faults in the lines $R, S$ and $R, T$ respectively. Figure 13 shows the firing impulse generators which are used for controlling two-phase faults.

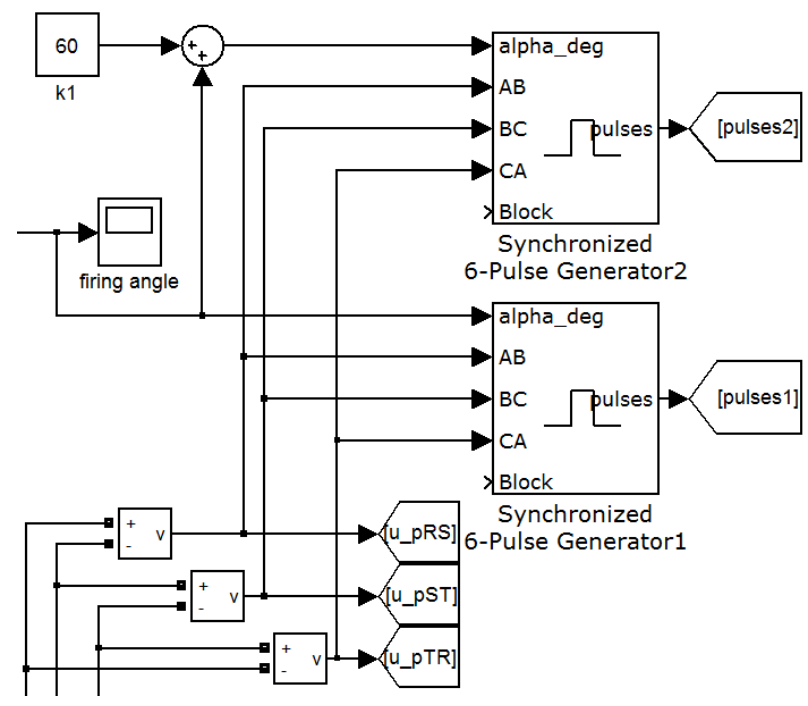

Figure 13: Firing impulse generators for two-phase faults in SIMULINK

Figure 14 shows the short-circuit currents and the firing angle of the controlled system for a two-phase fault between the lines $S$ and $T$. The described automatic fault detection was turned on; the fault was correctly detected, the firing pulses were set like shown in Table 1 and the system runs without increasing the pulse width. Figure 11 and Figure 14 are looking completely similar although the controlling principles are not the same.

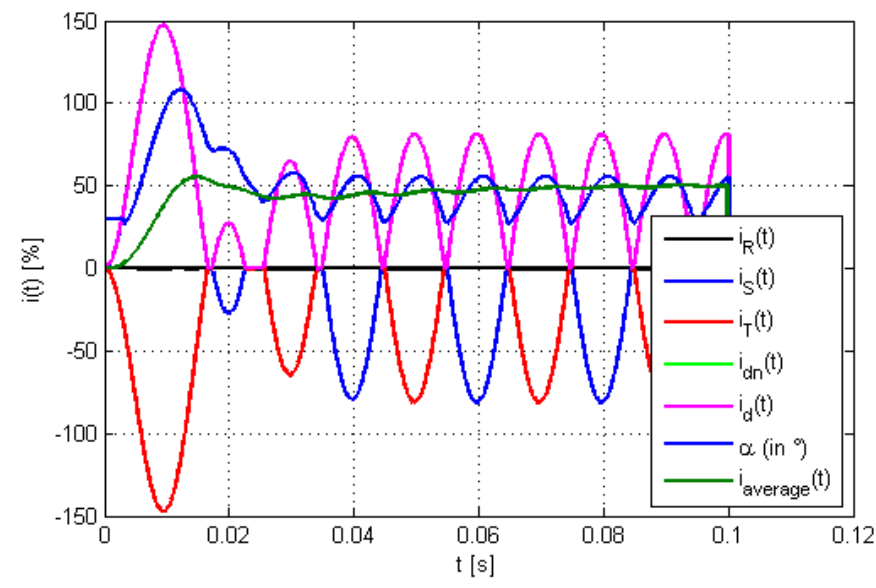

Figure 14: Controlled short-circuit currents at a two-phase fault for $Z_{d} / Z_{k}=0, K_{p}=1.8$ and $T_{N}=0.00 \overline{3}$ with modified pulse generator

\section{Conclusions}

The system performance of a FCL was investigated and hence the system could be identified. It was shown that the FCL reacts like a delay second order and that a controller could be designed by using the method of design with the help of the frequency response characteristic. Furthermore it was shown, that a dead-time element is existing which expresses itself in the firing delay of $60^{\circ}$ on average. The controller time constant could be chosen in order to compensate the linearized dead-time element and the controller gain could be chosen in order to damp the maximum aperiodic short-circuit current.

It was shown that the controller, which was developed for controlling three-phase short-circuit currents, could be used for single- and two-phase short-circuit currents too. Two changes are discussed for controlling two-phase short circuit currents. Either one has to increase the firing pulse width up to around $100^{\circ}$ or one has to install two firing impulse generators which are shifted $60^{\circ}$. Using this method also requires a fault type detection which was also discussed.

\section{REFERENCES}

[1] G. Herold, L. Gebhardt, V. Pfeiler, "Short-circuit current limitation in three-phase systems by means of inverters in bridge circuit (Kurzschlußstrombegrenzung in Drehstromsystemen mit Stromrichtern in Brückenschaltung)“, Electrie, vol. 34, 1980, pp. 554-556 (in german)

[2] W. Schulze-Buxloh, "Limitation of peak short-circuit currents in threephase systems (Begrenzung von Stoßkurzschlußströmen in Drehstromnezten)”, ETZ-A, vol. 95, 1974, pp. 426-427 (in german)

[3] M. Weiland, A. Schön, G. Herold, “Application of a Power Electronic Based Fault Current Limiter (FCL) to Reduce Arc Flash Energy in Electrical Grids with High Short-Circuit Power,” 14th European Conf. on Power Electronics and Applicat. (EPE), Brimingham, 2011

[4] H. Rubenbauer, G. Herold, "Determination of the Firing Angle for a Dynamic Fault Current Limiter (DFCL) in Case Without a Fault," $7^{\text {th }}$ International Conference on Power and Energy Systems, Palma de Mallorca (Spain), 2007

[5] M. Weiland, C. Hahn, G. Herold, "Control Strategies for Power Electronic Based Fault Current Limiter (FCL) in No-Fault Operation“, International Conf. on Renewable Energies and Power Quality (ICREPQ), Santiago de Compostela (Spain), 2012

[6] H. Rubenbauer, G. Herold, “A Dynamic Fault Current Limiter,” IEEE PES PowerAfrica 2007 Conference and Exposition, Johannesburg, South Africa, 2007, paper 127

[7] G. Herold, "Electrical power supply V, (Elektrische Energieversorgung V)“, J. Schlembach publishing, Wilburgstetten, Germany, 2009 (in german)

[8] H. Lutz, W. Wendt, "Pocketbook of control design, (Taschenbuch der Regelungstechnik)“, Deutsch Harri publishing, Frankfurt am Main, Germany, 2010 (in german) 